Original Article

\title{
Quality of life and life-space mobility after total knee arthroplasty in patients with rheumatoid arthritis: a pilot case-controlled study
}

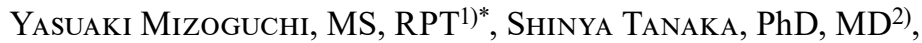 \\ Yukihiro Matsumoto, MS, RPT ${ }^{1)}$, Tsukasa UraKaWA, RPT ${ }^{1)}$, \\ Hitoshi Kurabayashi, PhD, MD ${ }^{1)}$, Kiyokazu Akasaka, PhD, RPT ${ }^{3)}$, Toby Hall, PhD, RPT ${ }^{4}$ 5) \\ 1) Department of Rehabilitation, Saitama Medical University Hospital: 38 Morohongo, Moroyama, \\ Iruma, Saitama 350-0495, Japan \\ 2) Department of Orthopedic Surgery, Saitama Medical University Hospital, Japan \\ 3) Master's and Doctoral Program of Physical Therapy, Saitama Medical University Graduate School \\ of Medicine, Japan \\ 4) School of Physiotherapy and Exercise Science, Curtin University, Australia \\ 5) Manual Concept, Australia
}

\begin{abstract}
Purpose] The purpose of this study was to identify factors inhibiting improvement in the quality of life after total knee arthroplasty in patients with rheumatoid arthritis. [Participants and Methods] This was a pilot case-control study. The sample comprised of five participants with rheumatoid arthritis and 11 participants with osteoarthritis, who underwent total knee arthroplasty. We compared the groups in terms of physical function, walking ability, Japanese Knee Osteoarthritis Measure, and Life-Space Assessment. Measurements were taken before surgery and at four weeks and five months post-surgery. All patients underwent rehabilitation for five months postoperatively, first as inpatients, and then as outpatients after discharge. [Results] In the period from 4 weeks to 5 months post-surgery, physical function improved similarly in both groups in terms of muscle strength and walking ability. Despite the patients with rheumatoid arthritis being younger, their self-health assessment score by the Japanese Knee Osteoarthritis Measure and measures of life-space mobility by Life-Space Assessment were lower. [Conclusion] It is important to consider exercise therapy, and gait instruction to alleviate anxiety about health status and improve the quality of life and life-space mobility in patients with rheumatoid arthritis who undergo total knee arthroplasty.

Key words: Rheumatoid arthritis, Quality of life, Life-space mobility
\end{abstract}

(This article was submitted Apr. 26, 2021, and was accepted Jun. 6, 2021)

\section{INTRODUCTION}

The primary purpose of total knee arthroplasty (TKA) is to improve pain, knee joint function and physical ability. The most common indication for surgery is knee osteoarthritis (OA) and 90\% of postoperative patients report improved pain and health-related quality of life (HRQOL) ${ }^{1,2}$. The patient satisfaction rate following surgery is very high $(85 \%)^{3)}$. Similarly, patients with rheumatoid arthritis (RA) also often require TKA surgery. Progress in drug therapy for RA has enabled suppression of joint destruction and disease activity, but knee deformity still occurs and is not improved by conservative treatment. Patients with decreased knee joint function are often provided with TKA to improve activities of daily living (ADL) ${ }^{4)}$. Many reports indicate that TKA surgery improves pain, joint function, and quality of life (QOL) in patients with RA six months

*Corresponding author: Yasuaki Mizoguchi (E-mail: yassunnyassunn@gmail.com)

(C2021 The Society of Physical Therapy Science. Published by IPEC Inc.

(c) (1) $\odot$ This is an open-access article distributed under the terms of the Creative Commons Attribution Non-Commercial No DerivaBY NC ND tives (by-nc-nd) License. (CC-BY-NC-ND 4.0: https://creativecommons.org/licenses/by-nc-nd/4.0/) 
after TKA surgery, but the improvement in QOL is not as great when compared to patients receiving surgery for knee $\mathrm{OA}^{5,6)}$. Polyarthritis, comorbidities, and combined use of multiple drugs may lead to psychological depression limiting interaction with others in those patients with RA. Actually, Singh et al. showed that patients with RA who underwent primary TKA had poorer ADL outcomes at 2 and 5 years than patients with $\mathrm{OA}^{7)}$. Therefore, it is considered that patients with RA have lower QOL and general activity levels after TKA when compared with patients with OA. In a 5 year follow-up study following lower limb joint arthroplasty, Momohara et al. reported that for RA, surgery helped reduce disease activity, but did not improve $\mathrm{HRQOL}^{8)}$. However, this report did not evaluate other factors including joint range of motion (ROM), muscle strength, or walking ability, and at the same time, did not assess knee joint disease-specific quality of life or everyday functional activity. To identify potential reasons why patients with RA do not obtain higher levels of HRQOL after receiving TKA, it is necessary to evaluate patient-based knee joint disease-specific QOL and actual activity, in addition to the measurement of lower limb function and walking ability.

Despite the fact that the recovery process of HRQOL, pain, function, and satisfaction after TKA may vary by race ${ }^{9)}$, there are few studies in Asia. In particular, the recovery process of ADL and quality of life of patients after TKA in the Japanese style of living is not clear. The Japanese Knee Osteoarthritis Measure (JKOM) is a self-completed patient-focused, disease-specific QOL questionnaire for OA that suits the Japanese lifestyle. The validity of this measurement index has been reported ${ }^{10)}$, and it can be used after TKA surgery. Besides this measure, a patient's actual activity can be quantified by using Life Space Assessment (LSA) ${ }^{11)}$. The LSA is an assessment tool that examines the distance and frequency with which patients go out on a daily basis in the last month. The Japanese Orthopaedic Association (JOA) knee score is an index developed by the Japanese Orthopedic Association to evaluate knee joint function, walking ability, and stair climbing ability as well as knee joint pain for patients with OA patients. It has demonstrated validity and reliability to measure physical function objectively ${ }^{12)}$.

The purpose of this study was to identify factors inhibiting improvement in QOL in patients with RA or OA by comparing lower limb function, walking ability, JKOM, and LSA up to 5 months after TKA.

\section{PARTICIPANTS AND METHODS}

This study was a pilot case-controlled study of patients receiving TKA in Saitama Medical University Hospital, Japan and reported by using the Strengthening the Reporting of Observational studies in Epidemiology checklist ${ }^{13)}$.

We compared outcome following TKA and postoperative rehabilitation in patients with RA or OA by measuring physical function, JKOM, and LSA preoperatively, four weeks postoperatively, and at five months postoperatively. In Japan, the fundamental upper limit of the number of rehabilitation days that can be supported by medical insurance is 150 days, so the final observation time was set at five months. This study was approved by the Institutional Review Board of Saitama Medical University Hospital (17-049-3). All the methods were performed in accordance with the relevant guidelines and regulations. During the recruitment, the study protocol was explained orally using paper with the information to all the recruited patients. Informed consent was obtained in the form of an opt-out on our website (http://www.saitama-med.ac.jp/hospital/outline/ irb_kouhou.html) from all patients in this study.

From January 2015 to January 2016, there were 51 cases receiving TKA surgery at our hospital. Among these, we chose patients with RA or OA, who had undergone evaluation before their operation, 4 weeks postoperatively, and 5 months postoperatively. Furthermore, we chose patients for the primary TKA. As a result, there were 16 cases ( 5 males, 11 females; age $71.1 \pm 6.6$ years: mean \pm SD) who met all of the above conditions. We excluded patients if they had any of the following criteria; 1) causative disease: idiopathic osteonecrosis of the knee joint; 2) If standard postoperative physical therapy could not be done due to intraoperative and/or postoperative complications; and 3) If patients are unable to perform outpatient physical therapy in our hospital and the evaluation is missing (Fig. 1). The case group participants consisted of patients with RA, as the purpose of the study was to identify factors inhibiting improvement in QOL after TKA in patients with RA. Participants in the control group were chosen from patients with OA. Controls were matched to the cases according to gender,

\begin{tabular}{|l|}
\hline Patients after primary TKA in 2015-2016 $(\mathrm{n}=51$ cases, 65 TKAs) \\
\hline $\begin{array}{l}\text { Excluded }(\mathrm{n}=35) \\
\text { - causative disease: idiopathic osteonecrosis of the knee joint }(\mathrm{n}=1) \\
\text { - If standard postoperative physical therapy could not be done due to } \\
\text { intraoperative and/or postoperative complications }(\mathrm{n}=2) \\
\text { - If patients are unable to perform outpatient physical therapy in our } \\
\text { hospital and the evaluation is missing }(\mathrm{n}=32)\end{array}$ \\
Completed measurement: 5 cases (RA patients) and 11 controls (OA patients) \\
\hline
\end{tabular}

Fig. 1. Flow diagram illustrating patient selection. 
BMI, preoperative walking status and number of rehabilitation times per week.

The participants in this sample comprised a group of 5 participants with knee RA in which 3 had bilateral TKA ( 2 joints used cruciate-retaining type [CR], 6 joints used posterior-stabilized type [PS]; 5 cases used para-patellar approach) and another group of 11 participants with knee OA in which 7 had bilateral TKA (14 joints of CR, 4 joints of PS; 7 cases used para-patellar approach, 4 cases used Trivector approach). The patients with RA in 5 cases underwent TKA due to RA lesions in the knee. The preoperative value of DAS28-CRP in patients with RA, was $3.45 \pm 1.53$ (range from 1.53-5.82; 1 case of remission, 3 cases of moderate disease, and 1 case of severe disease). As for drug therapy, all cases used methotrexate and prednisolone.

Physical therapy commenced on the second day post TKA. Simultaneously, we commenced range of motion exercises with the goal of achieving a knee flexion angle of 0-130 degrees during the hospitalization. Walking exercises were carried out at full load immediately with the aid of a wheeled walker and proceeded gradually to practice with a T-shaped cane. If there was no serious postoperative complication, the walking distance was set according to the patient's pain. Lower extremity strength training up to one week postoperatively was focused on open kinetic chain exercises in the supine or sitting position. We also started standing closed kinetic chain exercises one week after the operation, and performed stair climbing, bathtub entry/exit, floor movement, and outdoor walking exercises in stages. For outdoor walking practice, we prepared a course of about $300 \mathrm{~m}$ including a pedestrian crossing, a gentle slope, and steps without a handrail. The target postoperative hospital stay was 4 weeks. Physical therapy during hospitalization was performed 5 days a week, for 40-60 minutes per session. We instructed patients to a tailor-made self-training program that included ROM exercises, strength training for the quadriceps, hamstrings, and hip abductors in both weight-bearing and nonweight-bearing conditions, and gait exercises, using a brochure produced in our hospital. The postoperative hospital stay in each group was $32.4 \pm 10.5$ days in the RA group and $27.5 \pm 4.3$ days in the OA group. Both groups received physical therapy 5 times a week (40 minutes/time) during hospitalization and once a week (40-60 minutes/time) after discharge for 5 months.

The data source was our institution's electronic medical records. The survey items were gender, age at surgery, body mass index (BMI; $\mathrm{kg} / \mathrm{m}^{2}$ ), preoperative JOA knee score (points), preoperative and 5 months postoperative JKOM, walking status (with or without a T-shaped cane), unilateral or bilateral surgery, and LSA 5 months after surgery.

The JOA knee score is divided into four categories ${ }^{12)}$; "I: walking ability and presence/absence of knee joint pain (30 points)", "II: stair climbing ability and presence/absence of knee joint pain (25 points)", "III: knee joint flexion angle (35 points)", "IV: Knee joint swelling (10 points)", calculated on 100-points scale for each of the left and right knees, with 0 being the most severe. In the JOA knee score, in both cases, the left and right were compared, and the value on the lower side of the measured values, which is considered to affect the QOL and the spread of life, was adopted. This assessment was conducted by one of the doctors (S.T).

JKOM is divided into five categories ${ }^{10)}$; "I: Pain scale (VAS; visual analogue scale [mm])", "II: Pain and stiffness (8 items: 32 points)", "III: Condition in daily life (10 items: 40 points)", "IV: General activities (5 items: 20 points)", "V: Health conditions ( 2 items: 8 points)", calculated on 100-points scale for 25 items from II-V. Each item is classified into 5 levels (0-4 points), with 4 points being the most severe score. When answering the questionnaire, the patient answered at a location away from the physical therapist in charge. In JKOM, total JKOM score (total points) and each score of subcategory I-V were investigated.

Life range in LSA is set to six spaces ${ }^{11)}$; Life-Space 0 (Bed room), 1 (in the house), 2 (near the house), 3 (neighborhood), 4 (within town: $800 \mathrm{~m}$ to $16 \mathrm{~km}$ from home), 5 (outside of town: $16 \mathrm{~km}$ or more from home). The frequency of going out was based on Life-Space 0, how many times a week did you go to Life-Space 1-5 (1: daily, 2: 4-6 times a week, 3: 1-3 times a week, 4: less than once a week) are categorized. The LSA was evaluated by the physiotherapist in charge by asking the patient questions. We examined how many times a week the participant went to "life-Space 1-5" by categorizing it into two: "1: not less than 4 times a week" and "2: less than 4 times a week".

Postoperative physical function was evaluated at 4 weeks after surgery and 5 months after surgery, ROM (knee flexion and extension, degrees), isometric muscle strength ( $\mathrm{Nm} / \mathrm{kg}$; operative hip abduction, knee flexion, and knee extension), and timed up and go test (TUG, seconds). In terms of ROM and isometric muscle strength, we compared the left and right sides of the cases with bilateral TKA, and adopted the value on the lower side of the measured values that are more likely to affect QOL and the actual activity. The knee ROM was measured using a plastic goniometer (GS-100; OG Wellness Inc., Tokyo, Japan) passively in supine position. Isometric muscle strength was measured using the Hand-Held Dynamometer $\mu$ TAS F-1 (Anima Inc., Tokyo, Japan). Muscle contraction was carried out for 5 seconds, with maximum muscle force exerted after about 3 seconds from the start, in order to eliminate the influence of recoil. The left and right sides were measured three times and the maximum value was adopted. There was a rest of about 30 seconds between measurements on the same side and about 60 seconds between measurements on the left and right. The TUG was measured by the time taken to stand from sitting, walk $3 \mathrm{~m}$, turn around a cone, and return to the starting position ${ }^{14}$. In this study, we performed the measurement under maximum effort twice in order to minimize the fluctuation of the results due to differences in psychological state and the interpretation during measurement. We adopted the faster time as our data. JKOM, LSA, and physical function assessment were performed by physical therapists in our hospital. In order to reduce measurement error as much as possible, all physical functional tests were measured by four skilled physical therapists.

We calculated the sample size using power analysis application $\mathrm{G}^{*}$ Power 3.1.9.2 (http://www.gpower.hhu.de/). In order to 
compare physical function items, JKOM, and LSA between the RA and OA group, the effect size $\mathrm{d}$ was set to $0.5(\alpha=0.05$, $1-\beta=0.8)$ for the independent $t$-test and the effect size $w$ was set to $0.3(\alpha=0.05,1-\beta=0.8)$ for the $\chi^{2}$ test. We estimated that the level of effect size was medium for both analyses. As a result, the number of participants required were 128 cases (64 per group) for the t-test and 88 for the $\chi^{2}$ test. Therefore, we needed at least 128 patients. However, because this study was a pilot study with a small number of patients, we conducted a post hoc power analysis.

Gender, age, BMI, preoperative JOA knee score, unilateral TKA or bilateral TKA, presence or absence of walking aids preoperatively and 5 months postoperatively, and frequency of leaving the house at 5 months postoperative LSA, continuous variables were compared by an independent t-test or $\chi^{2}$ test. For the JKOM score prior to and 5 months after surgery in the two groups, and the changes over time in lower extremity function at 4 weeks and 5 months after surgery, split plot design ANOVA was performed to determine the main effects and interactions. When the main effect was significant, the MannWhitney U-test was used for group comparisons at each time point, and the Wilcoxon signed-rank test was used for within group comparisons for both groups. IBM SPSS Statistics for Windows, Version 25.0 (IBM Corp, 2017: Armonk, NY, USA) was used for these statistical analyses. The significance level was set to 5\%, and effect size determined for each analysis. Since the number of cases in this study was small, a post-power analysis was performed using G*Power 3.1.9.2.

\section{RESULTS}

We performed statistical analysis on 5 patients with RA and 11 patients with OA (Fig. 1). The RA group was significantly younger, and the preoperative JOA knee score was lower. Gender, BMI, preoperative walking status, and unilateral or bilateral TKA rates were not significantly different (Table 1).

In both groups, the hip abductor strength, knee flexion strength, knee extension strength, and TUG score significantly improved 5 months after the operation compared with 4 weeks after the operation. No significant difference was observed between the RA group and the OA group in any item or at any time point (Table 2).

In both groups, the total JKOM score and the "pain scale" score, "pain and stiffness" score, and "health conditions" score of the sub-category were significantly improved at 5 months comparing pre to post surgery. The "condition in daily life" score and "general activities" score of the sub-category were significantly improved in the OA group 5 months comparing pre to post surgery, but not in the RA group. The "pain scale" score of the subcategory before surgery was significantly lower in the RA group than in the OA group. The "health conditions" score of the sub-category was significantly higher in the RA group than in the OA group both before and after surgery (Table 3).

At 5 months postoperatively, walking status and LSA Space 1 (staying in the house) -3 (staying within the neighborhood) were not significantly different. However, the RA group reported significantly less frequently LSA Space 4 (staying within town) and Space 5 (venturing outside of town) compared to the OA group (Table 4).

\section{DISCUSSION}

The RA group was younger than the OA group and had a lower preoperative JOA knee score and a lower self-health assessment score, despite a lower preoperative "Pain scale" score in the JKOM sub-category. Both groups had similar improvements in muscle strength and walking ability, and both groups were comparable at 4 weeks and 5 months postoperatively in ROM of knee, muscle strength, and walking ability, but the RA group did not improve their "Condition in daily life" score and "General activities" score pre- to 5 months post-operatively, and despite rehabilitation their actual activity level in LSA was lower 5 months postoperatively.

As a characteristic of patients with RA, it has been reported that health assessed by physical activity and QOL are both decreased due to anxiety ${ }^{15-17)}$. Therefore, the disease of RA itself and its peripheral effects in terms of anxiety among other

Table 1. Patients demographic characteristic

\begin{tabular}{lccccc}
\hline & RA group $(\mathrm{n}=5)$ & OA group $(\mathrm{n}=11)$ & $\mathrm{p}$ & ES & $1-\beta$ \\
\hline Age $($ years) & $64.2 \pm 4.4$ & $74.2 \pm 4.8$ & $0.001^{*}$ & 0.73 & 0.99 \\
Gender (n) & male: 1 , female: 4 & male: 4 , female: 7 & 0.484 & 0.24 & 0.37 \\
BMI $\left(\mathrm{kg} / \mathrm{m}^{2}\right)$ & $25.6 \pm 3.7$ & $26.4 \pm 3.4$ & 0.665 & 0.12 & 0.11 \\
JOA knee score (points) & $42.0 \pm 5.7$ & $53.2 \pm 9.3$ & $0.027^{*}$ & 0.55 & 0.82 \\
Walking status (n) & without a cane: 1 & without a cane: 5 & 0.346 & 0.24 & 0.72 \\
& with a T-shaped cane: 4 & with a T-shaped cane: 6 & & & \\
Arthroplasty (n) & unilateral: 2 & unilateral: 4 & 0.654 & 0.07 & 0.06 \\
& bilateral: 3 & bilateral: 7 & & & \\
\hline
\end{tabular}

Independent t-test or $\chi^{2}$ test; ${ }^{*} \mathrm{p}<0.05$; Continuous variables are represented as Mean $\pm \mathrm{SD}$; The effect size (ES) was indicated by $\mathrm{r}$ for continuous variables and $\mathrm{w}$ for categorical variables; RA: rheumatoid arthritis; OA: osteoarthritis; BMI: body mass index; JOA: Japanese Orthopaedic Association. 
Table 2. Effect of time from operation and disease on knee function and walking

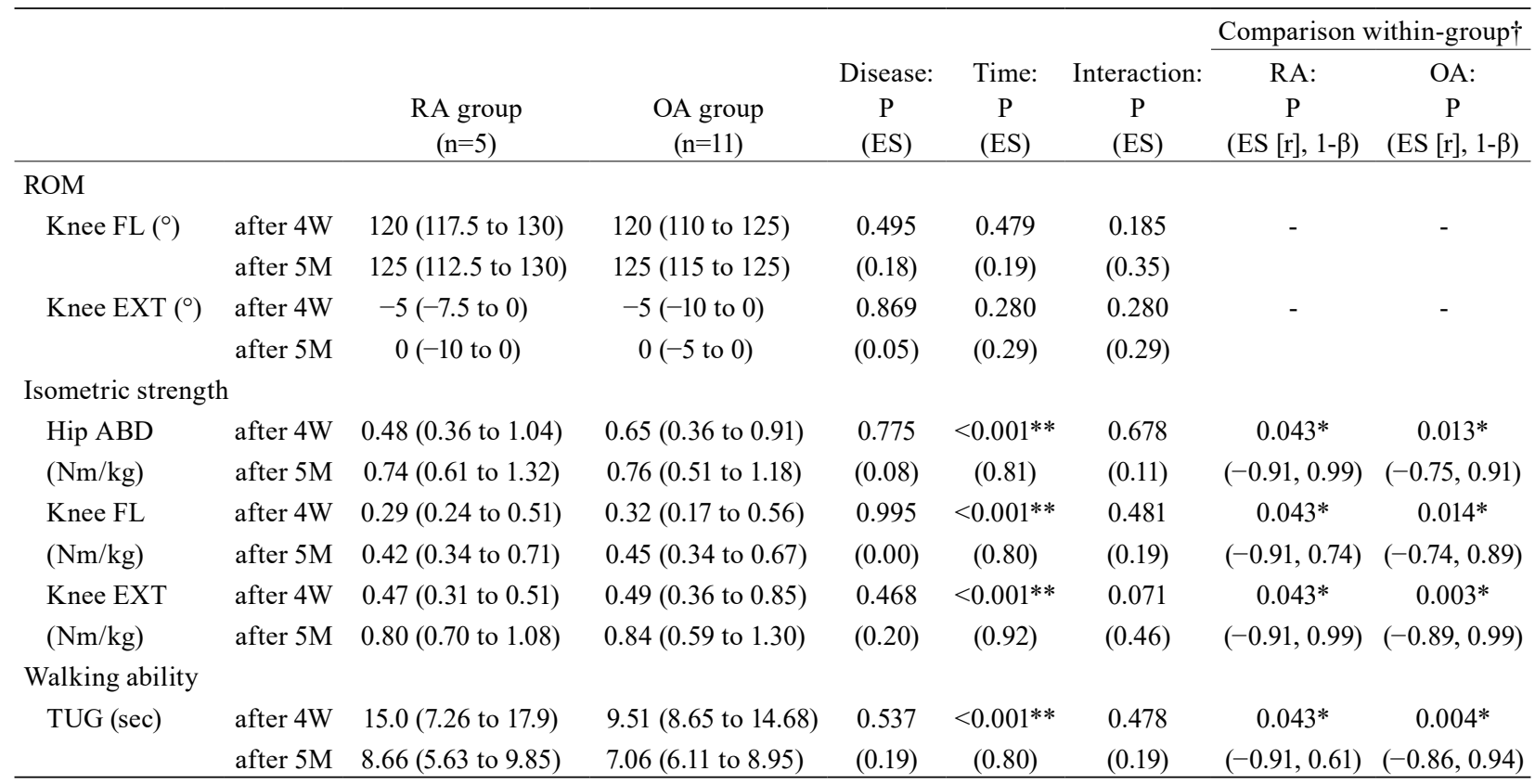

Split plot design ANOVA, ES: effect size; Continuous variables are represented as Median (25\%tile-75\%tile). $\dagger$ : Wilcoxon signed-rank test after split plot design ANOVA; ES: effect size $\mathrm{r} ;{ }^{*} \mathrm{p}<0.05 ;{ }^{* *} \mathrm{p}<0.001$; RA: rheumatoid arthritis; OA: osteoarthritis; ROM: range of motion; FL: Flexion; EXT: Extension; ABD: Abduction; TUG: timed up and go test (Measurement at maximum walking speed).

issue may be the reason why actual activity does not improve after TKA. Furthermore, this may be a factor in the decreased frequency of leaving the house and moving away from the town even 5 months after surgery. It is likely to be considered that TKA and rehabilitation are not enough to have an impact on the range and frequency which people can move.

Following TKA in patients with RA, it is essential for the physical therapist to have a broad understanding of the physical impairments and health issues pertaining to the individual patient needs. Rehabilitation should be targeted not just at improving range of motion and muscle strength, but also to expand QOL and confidence in moving outside the home. It has been reported that patients with RA with poor health assessments often need family support, and a team approach that includes family members can meet psychological needs, improve life functions, and eliminate anxiety ${ }^{18)}$. Conversely, performing aerobic exercise and strength training for RA patients also leads to improved self-health assessment and reduced support from people around them ${ }^{19,20)}$. In addition, it has reported that walking practice through obstacles such as pedestrian crossings, stairs, walking on an unpaved road, and going up and down a slope is helpful in expanding the living space for patients post-TKA ${ }^{21)}$. These approaches may lead to the long-term improvement of the patient's health assessment and independence of daily life.

Physical function from 4 weeks post-surgery to 5 months post-surgery, the RA group showed improvement in muscle strength and walking ability similar to the OA group. However, it is known that in general, skeletal muscle function and walking ability decline with age 22,23 . Despite being younger the RA group, showed similar results to the OA group at 4 weeks and 5 months post-surgery. Preoperative DAS28-CRP disease activity in the RA group in this study was classified as moderate to severe except in one case. It has been reported that about half of the patients with RA patients have moderate to severe disease activity with decreased walking speed and decreased physical activity ${ }^{24)}$. Considering that the rate of improvement of physical function in the RA group was rather high, there was probably disuse and muscle atrophy before TKA surgery due both to decreased health in general due to disease activity as well as and decreased physical activity on the knee. On the other hand, it has shown that physical therapy for patients with RA after TKA had the same effect of improving physical function as in the OA group. It has reported that continued resistance training in patients with RA reduces systemic inflammation, suppresses disease activity, and improves muscle strength ${ }^{25)}$. In addition to TKA, postoperative physical therapy may contribute to the improvement of physical function by reducing disease activity in patients with RA.

On the other hand, the results for the TUG test 5 months after surgery in both groups in this study were better than a previous report of patients with RA in HAQ-DI remission as well as Kellgren-Lawrence grade IV patients with OA (RA: 9.40-10.05 seconds, OA: 9.1 seconds) $)^{26,27)}$. However, the results for the TUG test were slower than community-dwelling older adults aged 75 years or older ${ }^{28)}$, and it can be said that the improvement of walking ability in both groups at 5 months after surgery is insufficient. It has been reported that walking ability 6 months after TKA is less than that for the healthy elderly ${ }^{29)}$, and it is important to provide training that can be continued at home at least for 6 months after surgery.

Our study has several limitations. First, the low number of cases being only 16 since operational constraints in our hospital 
Table 3. Effect of time from operation and disease on total JKOM score and sub-category scores

\begin{tabular}{|c|c|c|c|c|c|c|c|c|c|c|}
\hline & & \multirow[b]{2}{*}{$\begin{array}{l}\text { RA group } \\
\quad(\mathrm{n}=5)\end{array}$} & \multirow[b]{2}{*}{$\begin{array}{l}\text { OA group } \\
(\mathrm{n}=11)\end{array}$} & \multirow[b]{2}{*}{$\begin{array}{c}\text { Disease: } \\
\text { P } \\
(\mathrm{ES})\end{array}$} & \multirow[b]{2}{*}{$\begin{array}{c}\text { Time: } \\
\mathrm{P} \\
(\mathrm{ES})\end{array}$} & \multirow[b]{2}{*}{$\begin{array}{c}\text { Interaction: } \\
\mathrm{P} \\
\text { (ES) }\end{array}$} & \multicolumn{2}{|c|}{$\begin{array}{c}\text { Comparison } \\
\text { between-groups }{ }^{\dagger}\end{array}$} & \multicolumn{2}{|c|}{$\begin{array}{c}\text { Comparison } \\
\text { within-group }\end{array}$} \\
\hline & & & & & & & $\begin{array}{c}\text { pre-ope: } \\
\text { P } \\
(\mathrm{ES}[\mathrm{r}], 1-\beta)\end{array}$ & $\begin{array}{c}\text { after 5M: } \\
P \\
(\text { ES }[\mathrm{r}], 1-\beta)\end{array}$ & $\begin{array}{c}\text { RA: } \\
\text { P } \\
(\text { ES }[r], 1-\beta)\end{array}$ & $\begin{array}{c}\text { OA: } \\
\text { P } \\
(\mathrm{ES}[\mathrm{r}], 1-\beta)\end{array}$ \\
\hline $\begin{array}{l}\text { Total JKOM } \\
\text { score }\end{array}$ & $\begin{array}{l}\text { pre- } \\
\text { ope } \\
\text { after } \\
5 \mathrm{M}\end{array}$ & $\begin{array}{c}55 \\
(45 \text { to } 66.5) \\
28 \\
(14 \text { to } 38)\end{array}$ & $\begin{array}{c}63 \\
\text { (43 to } 73) \\
13 \\
(11 \text { to } 30)\end{array}$ & $\begin{array}{l}0.823 \\
(0.06)\end{array}$ & $\begin{array}{c}<0.001^{* *} \\
(0.89)\end{array}$ & $\begin{array}{l}0.258 \\
(0.30)\end{array}$ & - & - & $\begin{array}{c}0.043^{*} \\
(-0.91,0.57)\end{array}$ & $\begin{array}{c}0.003^{*} \\
(-0.89,0.99)\end{array}$ \\
\hline \multicolumn{11}{|c|}{ Sub-category of JKOM } \\
\hline $\begin{array}{l}\text { I: Pain scale } \\
\text { by VAS } \\
(\mathrm{mm})\end{array}$ & $\begin{array}{l}\text { pre- } \\
\text { ope } \\
\text { after } \\
5 \mathrm{M}\end{array}$ & $\begin{array}{c}44 \\
(29.5 \text { to } 62) \\
7 \\
(2.5 \text { to } 14.5)\end{array}$ & $\begin{array}{c}70 \\
\text { (50 to } 87) \\
5 \\
(1 \text { to } 21)\end{array}$ & $\begin{array}{l}0.048^{*} \\
(0.50)\end{array}$ & $\begin{array}{c}<0.001^{* *} \\
(0.91)\end{array}$ & $\begin{array}{l}0.092 \\
(0.44)\end{array}$ & $\begin{array}{c}0.041^{*} \\
(-0.51,0.57)\end{array}$ & $\begin{array}{c}0.820 \\
(-0.06,0.07)\end{array}$ & $\begin{array}{c}0.043^{*} \\
(-0.91,0.96)\end{array}$ & $\begin{array}{c}0.003^{*} \\
(-0.89,0.99)\end{array}$ \\
\hline $\begin{array}{l}\text { II: Pain and } \\
\text { stiffness }\end{array}$ & $\begin{array}{l}\text { pre- } \\
\text { ope } \\
\text { after } \\
5 \mathrm{M}\end{array}$ & $\begin{array}{c}13 \\
\text { (9 to } 22.5 \text { ) } \\
6 \\
\text { (2 to } 10.5 \text { ) }\end{array}$ & $\begin{array}{c}20 \\
\text { (18 to } 24) \\
5 \\
(3 \text { to } 10)\end{array}$ & $\begin{array}{l}0.188 \\
(0.35)\end{array}$ & $\begin{array}{c}<0.001^{* *} \\
(0.87)\end{array}$ & $\begin{array}{l}0.136 \\
(0.39)\end{array}$ & - & - & $\begin{array}{c}0.043^{*} \\
(-0.91,0.46)\end{array}$ & $\begin{array}{c}0.003^{*} \\
(-0.89,0.99)\end{array}$ \\
\hline $\begin{array}{l}\text { III: Condi- } \\
\text { tion in } \\
\text { daily life }\end{array}$ & $\begin{array}{l}\text { pre- } \\
\text { ope } \\
\text { after } \\
5 \mathrm{M}\end{array}$ & $\begin{array}{c}23 \\
\text { (18 to } 24.5) \\
9 \\
(2.5 \text { to } 16)\end{array}$ & $\begin{array}{c}20 \\
\text { (16 to } 31) \\
5 \\
(3 \text { to } 10)\end{array}$ & $\begin{array}{l}0.943 \\
(0.02)\end{array}$ & $\begin{array}{c}<0.001^{* *} \\
(0.87)\end{array}$ & $\begin{array}{l}0.363 \\
(0.24)\end{array}$ & - & - & $\begin{array}{c}0.068 \\
(-0.82,0.60)\end{array}$ & $\begin{array}{c}0.003^{*} \\
(-0.89,0.99)\end{array}$ \\
\hline $\begin{array}{l}\text { IV: General } \\
\text { activities }\end{array}$ & $\begin{array}{l}\text { pre- } \\
\text { ope } \\
\text { after } \\
5 \mathrm{M}\end{array}$ & $\begin{array}{c}12 \\
\text { (8.5 to } 16) \\
6 \\
(2 \text { to } 13.5)\end{array}$ & $\begin{array}{c}11 \\
\text { (3 to } 18) \\
3 \\
(2 \text { to } 5)\end{array}$ & $\begin{array}{l}0.403 \\
(0.23)\end{array}$ & $\begin{array}{l}0.007^{*} \\
(0.64)\end{array}$ & $\begin{array}{l}0.608 \\
(0.14)\end{array}$ & - & - & $\begin{array}{c}0.279 \\
(-0.49,0.17)\end{array}$ & $\begin{array}{c}0.013^{*} \\
(-0.75,0.87)\end{array}$ \\
\hline $\begin{array}{l}\mathrm{V} \text { : Health } \\
\text { conditions }\end{array}$ & $\begin{array}{l}\text { pre- } \\
\text { ope } \\
\text { after } \\
5 \mathrm{M}\end{array}$ & $\begin{array}{c}6 \\
(5.5 \text { to } 8) \\
3 \\
\text { (2 to } 5.5)\end{array}$ & $\begin{array}{c}4 \\
\text { (2 to } 6) \\
1 \\
\text { (1 to } 2)\end{array}$ & $\begin{array}{l}0.012^{*} \\
(0.61)\end{array}$ & $\begin{array}{c}<0.001^{* *} \\
(0.85)\end{array}$ & $\begin{array}{l}0.629 \\
(0.13)\end{array}$ & $\begin{array}{c}0.033^{*} \\
(-0.53,0.64)\end{array}$ & $\begin{array}{c}0.017^{*} \\
(-0.60,0.55)\end{array}$ & $\begin{array}{c}0.041^{*} \\
(-0.91,0.96)\end{array}$ & $\begin{array}{c}0.006^{*} \\
(-0.84,0.98)\end{array}$ \\
\hline
\end{tabular}

Split plot design ANOVA, ES: effect size. ${ }^{\dagger}$ : Wilcoxon signed-rank test or Mann-Whitney U-test after split plot design ANOVA, ES: effect size r; Continuous variables are represented as Median (25\%tile-75\%tile); ${ }^{*} \mathrm{p}<0.05 ;{ }^{* *} \mathrm{p}<0.001$; RA: rheumatoid arthritis; OA: osteoarthritis; JKOM: Japanese Knee Osteoarthritis Measure; VAS: visual analogue scale.

Table 4. Comparison of LSA at 5 months postoperatively and walking status

\begin{tabular}{|c|c|c|c|c|c|c|c|}
\hline \multirow[b]{2}{*}{ LSA } & \multicolumn{2}{|c|}{ RA group $(n=5)$} & \multicolumn{2}{|c|}{ OA group $(n=11)$} & \multirow[t]{2}{*}{$\mathrm{P}$} & \multirow[t]{2}{*}{ ES } & \multirow[t]{2}{*}{$1-\beta$} \\
\hline & $\geq 4$ times a week & $<4$ times a week & $\geq 4$ times a week & $<4$ times a week & & & \\
\hline $\begin{array}{l}\text { Space } 1(\mathrm{n}) \text { : } \\
\text { in the house }\end{array}$ & 5 & 0 & 11 & 0 & - & - & - \\
\hline $\begin{array}{l}\text { Space } 2(n): \\
\text { near the house }\end{array}$ & 5 & 0 & 10 & 1 & 0.688 & - & $<0.19$ \\
\hline $\begin{array}{l}\text { Space } 3(n) \text { : } \\
\text { neighborhood }\end{array}$ & 4 & 1 & 10 & 1 & 0.542 & 0.27 & 0.19 \\
\hline $\begin{array}{l}\text { Space } 4(n) \text { : } \\
\text { within town }\end{array}$ & 1 & 4 & 10 & 1 & $0.013^{*}$ & 0.77 & 0.99 \\
\hline $\begin{array}{l}\text { Space } 5(n) \text { : } \\
\text { outside of town }\end{array}$ & 0 & 5 & 9 & 2 & $0.005^{*}$ & - & $>0.99$ \\
\hline Walking status & $\begin{array}{r}\text { without } \\
\text { with a T-sh }\end{array}$ & $\begin{array}{l}\text { cane: } 3 \text {, } \\
\text { ped cane: } 2\end{array}$ & $\begin{array}{r}\text { without } \\
\text { with a T-sh }\end{array}$ & $\begin{array}{l}\text { cane: } 7 \text {, } \\
\text { ped cane: } 4\end{array}$ & 0.654 & 0.04 & 0.06 \\
\hline
\end{tabular}

$\chi^{2}$ test; ${ }^{*} \mathrm{p}<0.05$; The effect size (ES) was indicated by w for categorical variables; RA: rheumatoid arthritis; OA: osteoarthritis; LSA: life space assessment. 
did not allow further data collection. In addition, actual activities are affected by the living environment, such as the existence of a family living together and whether or not there is a need for the patient to drive the car by themselves, but the survey on driving was not included, and the results of this study are therefore not easy to be generalized. However, since some items with high statistical power were included, future research should focus more on these items. Besides, the condition of the knee joint on the non-operative side effects physical function, ADL, and QOL, however the non-operative side of the knee joint has not been considered in this study because of a small number of cases. It has been reported that there is no difference in improvement in function and QOL at 6 months postoperatively between bilateral and unilateral TKA ${ }^{30}$, hence, the combination of both in this study was acceptable. On the other hands, the sample size of patients with RA in this study was small. This may be due to the recent advances in RA pharmacological treatment. But, patients with RA who need surgery have a wide range of joint lesions, not only in the knee joint, but also in the ankle, foot, and upper extremity joints, and these factors may interfere with their ability to perform daily activities. In this study, we cannot determine how the condition of joints other than the knee affects the QOL and actual activities of patients with RA. Future studies will need to be conducted in larger numbers. Also, the results of this study were the QOL and actual activity at a maximum of 5 months for rehabilitation period as defined by Japanese law. It has been reported that LSA 6 months after TKA does not improve to the preoperative level ${ }^{31)}$, and it is necessary to consider longer-term evaluation in future studies. Finally, the present study was unable to match age between groups. JKOM after staged surgery for bilateral TKA was reported to be the same for younger and older patients ${ }^{32}$, and the results of the present study may reflect more differences by disease. However, it is essential to use more evident data in future research on this topic.

In this study, we conducted a pilot case-controlled study on physical function, JKOM, and LSA in patients with RA and OA who underwent TKA before surgery, 4 weeks after surgery, and 5 months after surgery. As a result, the postoperative physical function of patients with RA showed the same improvement as that of patients with OA patients, but the health assessment was lower than that for patients with OA, and it was revealed that the frequency of leaving the home and the local neighborhood was low 5 months after the operation. In order to obtain QOL and actual activity expansion of patients with RA who have undergone TKA, it is necessary to consider anxiety, the team approach, exercise therapy, and gait instruction in consideration of anxiety about health status. At 5 months after TKA, improvement in muscle strength and walking ability is insufficient, so continuous training may be required.

\section{Conference presentation}

A part of this report was presented at the 60th Annual General Assembly and Scientific Meeting of the Japan College of Rheumatology, Japan, in 2016 (URL: https://www.ryumachi-jp.com/meeting-education/proceeding/).

\section{Funding and Conflict of interest}

The authors have no conflicts of interest and funding to disclose.

\section{ACKNOWLEDGMENTS}

We would like to thank the physiotherapists at our hospital and patients for their help in collecting the data for this study. This study received no financial assistance.

\section{REFERENCES}

1) Price AJ, Alvand A, Troelsen A, et al.: Knee replacement. Lancet, 2018, 392: 1672-1682. [Medline] [CrossRef]

2) Carr AJ, Robertsson O, Graves S, et al.: Knee replacement. Lancet, 2012, 379: 1331-1340. [Medline] [CrossRef]

3) NIH Consensus Statement on total knee replacement. NIH Consens State Sci Statements, 2003, 20: 1-34. [Medline]

4) Wilkinson JM, Stanley D, Getty CJ: Surgical management of the rheumatoid patient. Curr Orthop, 2004, 18: 357-370. [CrossRef]

5) Dusad A, Pedro S, Mikuls TR, et al.: Impact of total knee arthroplasty as assessed using patient-reported pain and health-related quality of life indices: rheumatoid arthritis versus osteoarthritis. Arthritis Rheumatol, 2015, 67: 2503-2511. [Medline] [CrossRef]

6) Burn E, Edwards CJ, Murray DW, et al.: The effect of rheumatoid arthritis on patient-reported outcomes following knee and hip replacement: evidence from routinely collected data. Rheumatology (Oxford), 2019, 58: 1016-1024. [Medline] [CrossRef]

7) Singh JA, Lewallen DG: Better functional and similar pain outcomes in osteoarthritis compared to rheumatoid arthritis after primary total knee arthroplasty: a cohort study. Arthritis Care Res (Hoboken), 2013, 65: 1936-1941. [Medline] [CrossRef]

8) Momohara S, Inoue E, Ikari K, et al.: Efficacy of total joint arthroplasty in patients with established rheumatoid arthritis: improved longitudinal effects on disease activity but not on health-related quality of life. Mod Rheumatol, 2011, 21: 476-481. [Medline] [CrossRef]

9) Goodman SM, Parks ML, McHugh K, et al.: Disparities in outcomes for African Americans and Whites undergoing total knee arthroplasty: a systematic literature review. J Rheumatol, 2016, 43: 765-770. [Medline] [CrossRef]

10) Akai M, Doi T, Fujino K, et al.: An outcome measure for Japanese people with knee osteoarthritis. J Rheumatol, 2005, 32: 1524-1532. [Medline]

11) Baker PS, Bodner EV, Allman RM: Measuring life-space mobility in community-dwelling older adults. J Am Geriatr Soc, 2003, 51: 1610-1614. [Medline] [CrossRef] 
12) Okuda M, Omokawa S, Okahashi K, et al.: Validity and reliability of the Japanese Orthopaedic Association score for osteoarthritic knees. J Orthop Sci, 2012, 17: 750-756. [Medline] [CrossRef]

13) von Elm E, Altman DG, Egger M, et al. STROBE Initiative: The Strengthening the Reporting of Observational Studies in Epidemiology (STROBE) Statement: guidelines for reporting observational studies. Int J Surg, 2014, 12: 1495-1499. [Medline] [CrossRef]

14) Podsiadlo D, Richardson S: The timed "Up \& Go": a test of basic functional mobility for frail elderly persons. J Am Geriatr Soc, 1991, 39: 142-148. [Medline] [CrossRef]

15) Conigliaro P, Triggianese P, Ippolito F, et al.: Insights on the role of physical activity in patients with rheumatoid arthritis. Drug Dev Res, 2014, 75: S54-S56. [Medline] [CrossRef]

16) Qiu XJ, Zhang XL, Cai LS, et al.: Rheumatoid arthritis and risk of anxiety: a meta-analysis of cohort studies. Clin Rheumatol, 2019, 38: 2053-2061. [Medline] [CrossRef]

17) Machin AR, Babatunde $O$, Haththotuwa R, et al.: The association between anxiety and disease activity and quality of life in rheumatoid arthritis: a systematic review and meta-analysis. Clin Rheumatol, 2020, 39: 1471-1482. [Medline] [CrossRef]

18) Gettings L: Psychological well-being in rheumatoid arthritis: a review of the literature. Musculoskelet Care, 2010, 8: 99-106. [Medline] [CrossRef]

19) Nordgren B, Fridén C, Demmelmaier I, et al. PARA Study Group: An outsourced health-enhancing physical activity programme for people with rheumatoid arthritis: exploration of adherence and response. Rheumatology (Oxford), 2015, 54: 1065-1073. [Medline] [CrossRef]

20) Lange E, Kucharski D, Svedlund S, et al.: Effects of aerobic and resistance exercise in older adults with rheumatoid arthritis: a randomized controlled trial Arthritis Care Res (Hoboken), 2019, 71: 61-70. [Medline] [CrossRef]

21) Hiyama Y, Kamitani T, Mori K: Effects of an intervention to improve life-space mobility and self-efficacy in patients following total knee arthroplasty. J Knee Surg, 2019, 32: 966-971. [Medline] [CrossRef]

22) Yamada M, Moriguch Y, Mitani T, et al.: Age-dependent changes in skeletal muscle mass and visceral fat area in Japanese adults from 40 to 79 years-of-age. Geriatr Gerontol Int, 2014, 14: 8-14. [Medline] [CrossRef]

23) Hayashida I, Tanimoto Y, Takahashi Y, et al.: Correlation between muscle strength and muscle mass, and their association with walking speed, in communitydwelling elderly Japanese individuals. PLoS One, 2014, 9: e111810. [Medline] [CrossRef]

24) Tada M, Yamada Y, Mandai K, et al.: Correlation between frailty and disease activity in patients with rheumatoid arthritis: Data from the CHIKARA study. Geriatr Gerontol Int, 2019, 19: 1220-1225. [Medline] [CrossRef]

25) Verhoeven F, Tordi N, Prati C, et al.: Physical activity in patients with rheumatoid arthritis. Joint Bone Spine, 2016, 83: 265-270. [Medline] [CrossRef]

26) Kojima $T$, Ishikawa H, Tanaka S, et al.: Validation and reliability of the Timed Up and Go test for measuring objective functional impairment in patients with long-standing rheumatoid arthritis: a cross-sectional study. Int J Rheum Dis, 2018, 21: 1793-1800. [Medline] [CrossRef]

27) Amano T, Tanaka S, Ito H, et al.: Quantifying walking ability in Japanese patients with knee osteoarthritis: standard values derived from a multicenter study. J Orthop Sci, 2018, 23: 1027-1031. [Medline] [CrossRef]

28) Nishimura T, Imai A, Fujimoto M, et al.: Adverse effects of the coexistence of locomotive syndrome and sarcopenia on the walking ability and performance of activities of daily living in Japanese elderly females: a cross-sectional study. J Phys Ther Sci, 2020, 32: 227-232. [Medline] [CrossRef]

29) Bade MJ, Kohrt WM, Stevens-Lapsley JE: Outcomes before and after total knee arthroplasty compared to healthy adults. J Orthop Sports Phys Ther, 2010, 40: 559-567. [Medline] [CrossRef]

30) Huang YH, Lin C, Yang JH, et al.: No difference in the functional improvements between unilateral and bilateral total knee replacements. BMC Musculoskelet Disord, 2018, 19: 87. [Medline] [CrossRef]

31) Hiyama Y, Wada O, Nakakita S, et al.: Factors affecting mobility after knee arthroplasty. J Knee Surg, 2017, 30: 304-308. [Medline]

32) Sugita T, Miyatake N, Aizawa T, et al.: Quality of life after staged bilateral total knee arthroplasty: a minimum five-year follow-up study of seventy-eight patients. Int Orthop, 2019, 43: 2309-2314. [Medline] [CrossRef] 